\title{
Knowledge on Menstruation Among Adolescent School Girls in A Selected Area of Dhaka City
}

\author{
Nadira Parvin ${ }^{1}$ \\ Bonita Parvin' \\ Md Monoarul Haque 2* $^{*}$ \\ Mohammad Shahinoor Islam ${ }^{3}$ \\ 'Department of Public Health \\ Northern University Bangladesh. \\ ${ }^{2}$ Fellow, USAID. \\ ${ }^{3}$ Department of Public Health \\ BSMMU, Dhaka, Bangladesh.
}

\section{${ }^{*}$ Correspondence to:}

\section{Md Monoarul Haque}

Fellow, USAID, Bangladesh

Mobile : +8801915839550

Email:monoarmunna@yahoo.com

www.banglajol.info/index.php/CMOSHMCJ

\begin{abstract}
Background: Menstruation is one of the natural changes that occur in female in her normal life. Though it is a natural phenomenon, most of the adolescent girls have some wrong beliefs and behavior regarding menstruation. Objective: To assess knowledge on menstruation among adolescence school girls in a selected area of Dhaka City. Methods: A descriptive cross sectional study was conducted among conveniently selected 240 adolescent girls. A pre-tested modified questionnaire was used to get data by face to face interview. Knowledge level was determined by predefined scoring. Results: Mean age of respondents was $15.46+1.17$ years. Mean monthly family income of respondents was $22500 \pm 4256$ BDT. Majority of the respondents $(88 \%)$ did not have knowledge about menstruation before the onset of their menarche. Most of the respondents (88\%) were not mentally prepared for the first period. About $5.6 \%$ of the respondents felt good or normal during menstruation followed by $51 \%, 39.4 \%$ and $4 \%$ had uncomfortable, afraid and disgusting feeling respectively. Majority of the respondents (44\%) knew about menstruation from TV. Conclusion: Most of the respondents had poor knowledge/no knowledge about menstruation.
\end{abstract}

Key words: Knowledge; Menstruation; Adolescent girl.

\section{INTRODUCTION}

Adolescence is a social concept. Adolescence period is a very difficult time for young people. Adolescence, the second decade of life, is a period of rapid growth and development, when young people acquire new capacities and faced with many new situation that create not only opportunities for progress, but also a risk to health and well being. It is the time when growth is accelerated, major physical changes take place and difference between boys and girls are accentuated. According to the WHO in 2005, 50 percent of the world population were below the age of 25, i.e. one fourth of the world population are adolescents, 160 million live in developing countries and 91.3 million in the developed countries ${ }^{1}$. Although menarche is widely considered an important landmark in sexual maturity, and menstruation a natural event, studies have shown that it is a subject that is least understood even by married women, let along the teenage girls. In a study carried out in Jammu, India, the results showed that the majority of the women from both the rural and urban areas were unaware of actual physiological process of menstruation. Their explanation of the menstruation reflected incomplete knowledge and more typically a variety of misconceptions or ignorance. In attempting to explain menstruation, they ended up focusing on one particular element of the process that is blood/uterus ${ }^{2}$. A Nigerian study investigated 200 student's knowledge of, beliefs, attitude to and practices during menstruation and they showed only $5 \%$ respondents could correctly define menstruation. They used materials to manage menstruation include sanitary pad, pieces of cloths, toilet rolls, cotton wool, tampon and shoulder pad foam ${ }^{1}$. Information from this study will enable the development of programs to promote culturally sensitive and acceptable change in practices. 


\section{MATERIALS AND METHODS}

Study design: It was a descriptive cross sectional study.

Study population: Study population was adolescent school girls in a selected school of Dhaka city.

Study site: The study was carried out in ward no. 2 of Dhaka North City Corporation, Mirpur, Dhaka, Bangladesh.

Study area: Monipur High School \& College is a secondary school \& college located in Mirpur, Dhaka, Bangladesh. Around 20,500 students including boys and girls are currently studying at Monipur High School \& College.

Study period: The study was conducted during the period from September 2014 to December 2014.

Sample size: Due to shortage of budget and time limitation researcher took 240 samples.

Inclusion criteria: Those Adolescent school girls aged between 12 and 18 years and who gave informed consent to participate in the study.

Exclusion criteria: Those who refused to give informed consent.

Sampling technique: Non probability convenient sampling technique was applied for the study.

Data collection tools: Data were collected by using a pretested modified questionnaire.

Data collection technique: By face to face interview.

Data management and analysis: Data were entered on the computer programs Statistical Package for Social Science (SPSS 16.0, Chicago). Cleaned and processed data was presented in the form of tables and charts. Finally the data was interpreted on the basis of study findings.

Knowledge: It is very difficult to quantify one's knowledge level but I tried to know some aspect of knowledge by fixing some questions about different arena of menstruation.

\section{RESULTS}

Mean age of respondents was $15.46+1.17$ years. Majority of the respondent's mother's $(43.75 \%)$ education was secondary level and $32.08 \%, 12.5 \%, 11.67 \%$ was higher secondary, graduate and primary respectively. Housewife and service holder was $60.41 \%$ and $22.08 \%$. Mean monthly family income of respondents was $22500 \pm 4256$ BDT. Most of them were muslim. (Table-1) Table no. 2 shows that majority of the respondents (88\%) did not have knowledge about menstruation before the onset and rest of them $12 \%$ had knowledge. Figure-1 shows that most of the respondents (88\%) were not mentally prepared for the first period and rest of them (12\%) were prepared. Figure 2 shows that majority of the respondents (44\%) knew about menstruation from TV followed by $22 \%, 16 \%, 3 \%, 9 \%$ and $6 \%$ from radio, newspaper, poster, group discussion and health worker respectively. Table 3 shows that $5.6 \%$ of the respondents had felt good or normal during menstruation followed by $51 \%, 39.4 \%$ and $4 \%$ had uncomfortable, afraid and disgusting feeling respectively. Table 4 reveals that $9 \%$ of the respondents' feeling for menstruation was good remaining to $51 \%, 26 \%$ and $14 \%$ was uncomfortable, Ok and disgusting feeling respectively.
Table 1: Socio-demographic characteristics of the study subjects $(\mathrm{n}=240)$.

\begin{tabular}{lrr} 
Items & Frequency $(\%)$ & Mean $( \pm$ SD) \\
Age in Years & & $15.46 \pm 1.176$ \\
Education of mother & & \\
Primary & $28(11.67)$ & \\
SSC & $105(43.75)$ & \\
HSC & $77(32.08)$ & \\
Graduate & $30(12.5)$ \\
Occupation of mother & \\
Service & $53(22.08)$ \\
Business & $22(9.17)$ \\
Jobless & $20(8.34)$ \\
Housewife & $145(60.41)$ \\
Monthly family income & \\
Religion & \\
Muslim & \\
Hindu & $154(64)$ \\
Christian & $50(21)$ \\
Buddhist & $26(11)$ \\
Total & $10(4)$ \\
\hline
\end{tabular}

Table 2: Distribution of the respondents by knowledge about menstruation before the onset of their menarche $(n=240)$.

\begin{tabular}{lcc} 
Knowledge & Frequency & Percent \\
Yes & 74 & 12.0 \\
No & 166 & 88.0 \\
Total & 240 & 100.0 \\
\hline
\end{tabular}

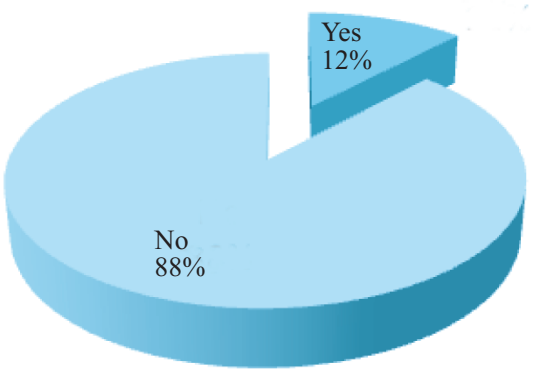

Figure 1: Distribution of the respondents by mental preparation for the first menstrual bleeding $(\mathrm{n}=240)$.

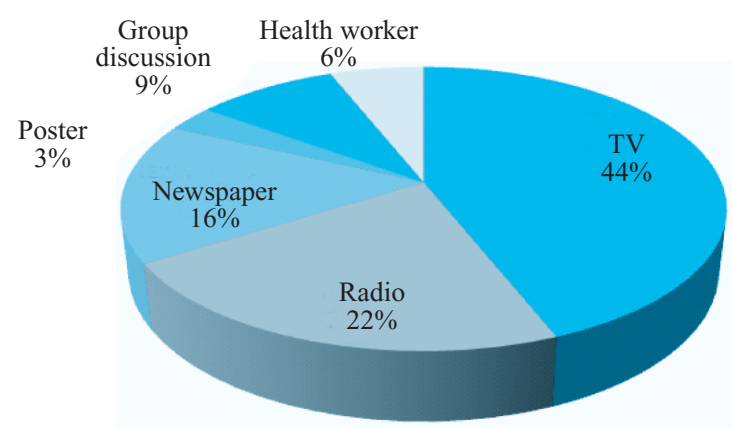

Figure 2 : Distribution of the respondents by source of information $(\mathrm{n}=240)$. 
Table 3: Distribution of the respondents by first menstrual feelings $(n=240)$.

First menstrual feeling

Good or normal

Uncomfortable

Afraid

Disgusting

Total

Frequency

24

107

86

23

240

Percent

5.6

51.0

39.4

4.0

100.0

Table 4: Distribution of the respondents by present feeling $(n=240)$.

\begin{tabular}{lcc} 
Present feeling & Frequency & Percent \\
Good & 31 & 9.0 \\
Uncomfortable & 99 & 51.0 \\
Ok & 65 & 26.0 \\
Disgusting & 45 & 14.0 \\
Total & 240 & 100.0 \\
\hline
\end{tabular}

\section{DISCUSSION}

Since socio-economic conditions have long been known to influence adolescent health, it plays an important role in human health. Clients from lower socio-economic level tend to value health promotion behavior less than the clients from higher socio-economic level. Individuals who belong to lower socioeconomic status are often less motivated to seek health care education ${ }^{3}$. Socioeconomic status of this study was closure to a study conducted in China at $2005^{4}$. Menstruation has had ageold social and psychological significance; taboos, proscription, myths and superstition persist even in advanced and scientifically enlightened society ${ }^{5}$. The embarrassment surrounding menstruation is a somewhat universal phenomenon, found in most cultures of the world and with many associated code words, euphemisms and phrases used as linguistic substitutes ${ }^{6}$.
It showed that majority of the respondents $(88 \%)$ did not have knowledge about menstruation before the onset of their menarche. The study was different from a study conducts in India in 1994 may be due to different religious settings ${ }^{7}$. A study done in China, on psychosocial and cultural factors influencing expectation of menarche revealed that participants expectation of menarche were largely negative and heavily influenced by cultural beliefs about menstruation ${ }^{8}$. College women accepted menstruation rather routinely and did not perceive it as overly disruptive. But the beliefs about menstruation are more complex than previously thought, involving differential perceptions of physical versus psychological symptoms and a variety of dimensions of menstrual related attitudes ${ }^{9}$. It was found that most of the respondents $(88 \%)$ were not mentally prepared for the first menstrual bleeding. Study showed that 5.6\%, 51\%, 39.4\% and $4 \%$ of the respondents had good or normal, uncomfortable, afraid and disgusting feeling respectively during menstruation. The study revealed that $9 \%, 51 \%, 26 \%$ and $14 \%$ respondents feeling for menstruation was good, uncomfortable, ok and disgusting respectively. These information were different from a study conducted in Taiwan in 2004 might be due to cultural variation ${ }^{10}$.

\section{CONCLUSION}

The knowledge of the respondents on the overall menstruationits onset, cycle, common problems, complications, treatmentvary, and their knowledge is particularly poor on the technical aspects of reproductive cycle.

\section{ACKNOWLEDGMENT}

The authors express their sincere thanks to all the participants of this study.

\section{DISCLOSURE}

All the authors declared no competing interest. 


\section{REFERENCES}

1. Irinoye OO, Ogungbemi A, Ojo AO. Menstruation: Knowledge, attitude and practices of students in life, Nigeria. Niger J Med. 2003;12(1):43-51.

2. Drakshayani DK, Venkata RP. A study of menstrual hygiene among rural adolescent girls. Indian Journal of Medical Science. 1994;48(6):139-143.

3. Adhikary P, Kadel B, Dhungel S, Mandal A. Knowledge and practice regarding menstrual hygiene in rural adolescent girls of Nepal. Kathmandu University Medical Journal. 2007; 5(3):382.

4. Yeung DYL, Tang CS, Lee A. Psychosocial and cultural factors influencing expectations of menarche: A study on Chinese premenarcheal teenage girls. Journal of Adolescent Research. 2005;20 (1):118.

5. Concern women for family planning. Adolescent reproductive Health and right:Perception, Attitude and Knowledge. Dhaka: The organization. 1998.

6. Brudtland S. Reproductive: The young right to know. Med. 1999;15(4):29-36.

7. John C C, Leo BH. The nature of adolescence. London. 1999;(2,3):22- 23.

8. Nahar Q Amin, Sultan R, Nazrul H, Islam M,Kane T T et al. Strategies to meet the health need of adolescent: A Review. Dhaka: ICDDRB: 1999.

9. Stubbs ML. Developmental differences in menstrual attitudes. Journal of early adolescence. 1989; 9(4):480-498.

10. Cheng Yu C (Primary investigator). Knowledge and attitudes towards menstruation among Taiwanese adolescents. Conference sponsor: Midwest Nursing Research Society. 2004. Virginia Henderson International Nursing Library. Available from URL:http://www.nursinglibrary.org/Portal/main.aspx?pageid=4040\&PID=5918\&version ID=1 \& 2008/2/22 